\title{
Analisis Miskonsepsi Pelayanan Bimbingan dan Konseling di SMA dan MAN Idi Rayeuk
}

Khairirani ${ }^{1}$, Muhammad Nasir ${ }^{2}$, Rizky Andana Pohan ${ }^{3}$

${ }^{13}$ Bimbingan dan Konseling Islam IAIN Langsa, Indonesia,

1khairirani010498@gmail.com 2 hilwa.umam@gmail.com, ${ }^{3}$ Andana Pohan@iainlangsa.ac.id,

\begin{tabular}{c|cc} 
First received: & Revised: & Final Accepted: \\
10 Oktober 2021 & 02 November 2021 & 24 November 2021
\end{tabular}

\begin{abstract}
Misconception is a wrong explanation and an idea that is incompatible with the scientific understanding accepted by the experts. Misconceptions often occur because the concepts learned and accepted by students are different. The purpose of this study was to determine how the misconception of guidance and counseling services in SMA and MAN Idi Rayeuk. This research was conducted using qualitative descriptive methods with data collection techniques through observation, interviews and documentation. The results of this study explain that the misconception of guidance and counseling services in MAN 1 Idi Rayeuk still occurs because the teacher who serves as a counseling teacher is not a BK teacher but is a graduate of Sociology who is given the responsibility to solve student problems. less because they do not understand the theory and how to implement the BK services provided to students to deal with their problems. Meanwhile, in SMA N 1 Idi Rayeuk, misconceptions do not occur, because the teachers who provide BK services are graduates of S-1 guidance and counseling. For the service and implementation of the BK program has started to be carried out well because BK teachers are able to carry out their duties in implementing BK services in accordance with the operational guidelines for the implementation of guidance and counseling for high school (SMA).
\end{abstract}

Keywords: Misconception, Guidance and Counseling Services

\begin{abstract}
Abstrak
Miskonsepsi merupakan penjelasan yang salah dan suatu gagasan yang tidak sesuai dengan pengertian ilmiah yang di terima para ahli. Miskonsepsi sering terjadi karna konsep yang dipelajari dan diterima oleh siswa berbeda-beda. Tujuan penelitian ini adalah untuk mengetahui bagaimana miskonsepsi pelayanan bimbingan dan konseling di SMA dan MAN Idi Rayeuk. Penelitian ini dilakukan dengan menggunakan metode deskriptif kualitatif dengan teknik pengumpulan data melalui observasi, wawancara dan dokumentasi. Hasil penelitian ini menjelaskan bahwa miskonsepsi pelayanan bimbingan dan konseling di MAN 1 Idi Rayeuk masih terjadi karena guru yang bertugas sebagai guru BK bukan tamatan BK melainkan guru tersebut tamatan dari Sosiologi yang di beri tanggung jawab untuk mengatasi masalah siswa, dalam pelaksanaan pelayanan BK pun masih sangat kurang karena tidak memahami teori dan bagaimana penerapan pelayanan BK yang di berikan kepada siswa untuk menangani permasalahannya. Sedangkan di SMA N 1 Idi Rayeuk miskonsepsi sudah tidak terjadi, karena guru yang memberikan layanan BK adalah tamatan S-1 bimbingan dan konseling. Untuk pelayanan dan pelaksanaan program BK sudah mulai terlaksanakan dengan baik karena guru BK mampu melaksanakan tugasnya dalam menerapkan pelayanan BK sesuai dengan panduan operasional penyelenggaraan bimbingan dan konseling sekolah menengah atas ( SMA).
\end{abstract}

Kata Kunci: Miskonsepsi , Pelayanan Bimbingan dan Konseling 


\section{PENDAHULUAN}

Miskonsepsi adalah salah satu konsep yang merujuk pada suatu konsep yang tidak sesuai dengan pengertian ilmiah. bentuk miskonsepsi dapat berupa konsep awal, kesalahan, hubungan yang tidak bena rantara konsep-konsep, gagasan intutif atau pandangan yang tidak benar. Miskonsepsi terjadi karena kesalahan yang di lakukan seseorang dalam membangun konsepsi berdasarkan informasi lingkungan fisik di sekitarnya atau teori yang di terima, salah satu penyebab miskonsepsi adalah anak cenderung memahami kejadian bagian per bagian dan cenderung tidak mengaitkan satu bagian dengan bagian lainnya (Diniati, A. 2018).

Kondisi miskonsepsi apabila dibiar kan tentu saja akan berbahaya mengingat apabila kondisi ini dibiarkan menetapakan berdampak pada penerimaan konsep selanjutnya. Miskonsepsi yang dialami setiap siswa di sekolah bisa berlainan dengan penyebab yang berbeda-beda (Deliani, N. 2018; Yulianti, Y. 2017). Oleh karena itu, sangat penting bagi guru untuk mengenali miskonsepsi beserta penyebab nya yang terjadi pada masing-masing siswa. untuk mengetahui penyebabnya maka harus dilakukan layanan bimbingan konseling di sekolah untuk mengetahui penyebabnya (Rosmalia, L. P. 2016).

Dalam pelaksanaan Bimbingan dan Konseling di sekolah di selenggarakan dengan pola yang tidak jelas, ketidakjelasan pola yang harus diterapkan berdampak pada buruknya citra bimbingan dan konseling, sehingga melahirkan miskonsepsi terhadap pelaksanaan BK (Ramlah, 2018). Munculnya persepsi negatif terhadap pelaksanaan Bimbingan Konseling, berbagai kritikan muncul sebagai wujud kekecewaan atas kinerja guru pembimbing sehingga terjadi kesalahpahaman, persepsi negatif dan miskonsepsi yang berlarutlarut (Heldayani, B. 2016). Masalah yang sering menjadi kesalahpahaman terhadap Bimbingan konseling di sekolah ialah:

1. Guru Bimbingan Konseling seringdi anggap sebagai polisi sekolah.

2. Bimbingan Konseling sering dianggap sebagai media pemberi nasehat.

3. Bimbingan Konseling dianggap hanya mengatasi kasus siswa yang bermasalah.

4. Guru Bimbingan konseling harus lebih aktif dalam mengatasi masalah siswa.

5. Profesi sebagai guru bimbingan konseling bisa dilakukan oleh siapa saja .

Kesalahpahaman ini perlu dilakukan pencegahan agar tidak menyebar, dan selanjutnya perlu dilakukan penyelesaian agar proses pelayanan bimbingan dan konseling dapat berjalan dengan baik sesuai dengan kaidah keilmuan yang telah di tetapkan. Pelayanan bimbingan dan konseling disekolah sangat diperlukan karena setiap siswa disekolah dapat dipastikan memiliki masalah,baik masalah pribadi maupun masalah dalam belajarnya, dan setiap 
masalah yangd ihadapi masing-masing siswa sudah pastilah berbeda.

Untuk dapat mengatasi masalah tersebut perhatian dan peranan guru bimbingan konseling sangat dibutuhkan. Permendikbud (2014) menyatakan Bimbingan dan konseling adalah proses pemberian bantuan kepada siswa guna membantu mereka memperoleh pengetahuan dan keterampilan dalam membuat pilihan-pilihan dan rencanarencana yang diperlukan untuk menyesuaikan diri dengan baik yang dilakukan secara tatap muka antara peserta didik dengan konselor untuk dapat memecahkan permasalahan yang dialami oleh siswa (klien).

Untuk menjelaskan ruang lingkup yang akan di teliti dengan tujuan agar masalah yang di teliti tersebut tidak terlalu luas dan keseluruhan kegiatan penelitian lebih terpusat,maka peneliti membuat batasan masalah berupa :

1. Analisis Miskonsepsi pelayanan bimbingan dan konseling.

2. Subjek yang menjadi penelitian adalah Guru BK, Kepala Sekolah dan Siswa.

3. Objek penelitian dalam pembahasan ini adalah SMA N 1 Idi Rayeuk dan MAN 1 Idi Rayeuk.

\section{METODE}

Jenis penelitian ini adalah penelitian kualitatif deskriptif, yaitu data yang dikumpulkan berbentuk kata-kata, gambar, bukan angka-angka (Arikunto, S. 2002). Menurut Bogdan dan Taylor,sebagaimana yang dikutip oleh
Moleong, L, J (2017) penelitian kualitatif adalah prosedur penelitian yang menghasilkan data deskriptif berupa katakata tertulis atau lisan dari orang-orang dan perilaku yang diamati.

Menurut Sugiyono (2016), dalam penelitian kualitatif teknik sampling yang lebih sering digunakan adalah purposive sampling dan snow ball sampling. purposive sampling adalah teknik pengambilan sampel sumber data dengan pertimbangan tertentu, sedangkan snow ball sampling adalah teknik pengambilan sampel sumber data yang pada awalnya jumlah sampel yang sedikit, semakin lama semakin banyak. sementara itu menurut Bungin, B (2008) dalam prosedur sampling yang paling penting adalah bagaimana menentukan informan kunci atau situasi social tertentu yang mengetahui banyak informasi yang diperlukan.sampel dalam penelitian ini adalah Guru BK, Kepala Sekolah dan siswa.

\section{HASIL TEMUAN}

Untuk Miskonsepsi pelayanan bimbingan dan konseling itu sendiri di SMA dan MAN sangat berbeda, yang mana bahwa SMA sudah adanya perkembangan dan pembaharuan terhadap bimbingan dan konseling itu sendiri, guru yang ahli di bidang BK pun ada di SMA dan membuat perubahan pada sistem sekolah, dan ini merupakan tugas ataupun bagian peran yang penting untuk membuat BK lebih berkembang dan diterima oleh lingkungan sekitar. tidak hanya itu guru BK yang memang ahli di bidang BK akan mengetahui langkah apa saja yang harus 
dilakukan dan strategi seperti apa yang harus diambil agar BK menjadi pusat perhatian siswa-siswi SMA tersebut dan mereka tertarik untuk berbagi cerita dan nyaman dengan BK itu sendiri, nilai yang paling positifnya saat peneliti melakukan observasi pendekatan yang dilakukan guru BK benar-benar membuat siswa di SMA tertarik dan mau berbagi cerita dan permasalahan yang terjadi dengan siswa tersebut diceritakan kepada guru BK.

Untuk Sekolah MAN sudah pasti adanya miskonsepsi, karena guru yang ditugaskan di bidang BK bukan guru yang berprofesi di bidang BK melainkan guru tersebut tamatan dari sosiologi, sedangkan dalam bidang bimbingan dan konseling banyak mempelajari teori dan terapi mengenai bagaimana penanganan siswa yang bermasalah. oleh sebab itu guru tersebut belum efektif dalam menjalankan tugasnya sebagai guru BK. dalam menyelesaikan permasalahan siswa pun jika kesalahan yang terjadi masih terulang lagi maka guru BK tersebut akan memberikan hukuman seperti : pemanggilan orang tua, memarahi siswa, dan jika sudah di nasehati berkali-kali maka siswa akan di kembalikan ke orang tua nya atau akan dikeluarkan dari sekolah. maka dari itu kebanyakan siswa beranggapan bahwa BK adalah tempat pemanggilan siswa yang bermasalah. dan di MAN tidak adanya ruang BK. guru yang bertugas di BK hanya belajar dari pengalaman dan hanya mencari informasi melalui buku dan lainnya untuk menambah wawasan, dan saat peneliti melakukan wawancara dengan guru BK jawaban dari pertanyaan yang peneliti berikan tidak berdasarkan pada POP BK. untuk itu agar kesalahpahaman tentang BK tidak semakin menyebar luas maka kepala sekolah wajib membuat seminar tentang penting nya BK di sekolah dan mengundang pemateri yang memang ahli di bidang BK sehingga dengan begitu kesalahpahaman tentang $\mathrm{BK}$ sedikit berkurang.

Tabel : Analisis Miskonsepsi Pelayanan Bimbingan dan Konseling di SMA N 1 Idi Rayeuk dan MAN 1 Idi Rayeuk.

\begin{tabular}{|l|l|l|c|}
\hline No. & Indikator & $\begin{array}{l}\text { Miskonsepsi } \\
\text { Pelayanan } \\
\text { BK }\end{array}$ \\
\hline & $\begin{array}{l}\text { Pelaksanaan } \\
\text { tugas guru } \\
\text { BK }\end{array}$ & $\begin{array}{l}\text { SMA } \\
\text { MAN }\end{array}$ \\
\hline 1. & $\begin{array}{l}\text { Pemahaman } \\
\text { Karakter } \\
\text { Peserta Didik }\end{array}$ & - & $\sqrt{ }$ \\
\hline 2. & $\begin{array}{l}\text { Perencanaan } \\
\text { Program } \\
\text { Bimbingan } \\
\text { dan } \\
\text { Konseling }\end{array}$ & - & $\sqrt{ }$ \\
\hline 3. & $\begin{array}{l}\text { Pelaksanaan } \\
\text { Program } \\
\text { Bimbingan } \\
\text { dan } \\
\text { Konseling }\end{array}$ & $\begin{array}{l}\text { Pelaporan } \\
\text { dan Tindak } \\
\text { Lanjut }\end{array}$ & - \\
\hline 4 & $\begin{array}{l}\text { Evaluasi, } \\
\text { Perasarkan }\end{array}$ & $\sqrt{ }$ \\
\hline
\end{tabular}

Berdasarkan hasil temuan peneliti dengan temuan kajian terdahalu pada jurnal Bimbingan dan Konseling Islam 
mengenai miskonsepsi dalam pelaksanaan BK hampir memiliki kesamaan karena pada temuan kajian terdahulu membahas tentang miskonsepsi dalam BK yang dibahas secara khusus yang berkaitan dengan pelaksanaan konseling individu dan bimbingan belajar yang mana pada temuan terdahalu masih saja terjadi kesalahpahaman dalam dunia pendidikan dalam proses belajar mengajar sehingga dengan begitu miskonsepsi yang terjadi semakin sulit untuk di perbaiki karena konsep yang dipelajari dan diterima sebelumnya sangat berbeda. sedangkan pada temuan yang saya lakukan juga masih membahas tentang miskonsepsi akan tetapi secara umum yang sering terjadi didalam dunia pendidikan,dari

\section{PEMBAHASAN}

Miskonsepsi merupakan penjelasan yang salah dan suatu gagasan yang tidak sesuai dengan pengertian ilmiah yang di terima para ahli. Miskonsepsi dapat merupakan tentang konsep yang tidak akurat, penguasaan konsep yang salah, klarifikasi contoh-contoh yang salah tentang penerapan konsep, pemaknaan konsep yang berbeda dan hubungan konsep-konsep yang tidak benar. Miskonsepsi secara umum dapat dijelaskan sebagai suatu pandangan yang salah dan mendefinisikan nya sebagai suatu gagasan yang tidak sesuai dengan pengertian ilmiah yang sekarang diterima.

Sedangkan dalam layanan bimbingan dan konseling layanan yang diberikan merupakan upaya sistematis, objektif, logis, dan berkelanjutan serta terprogram yang dilakukan oleh konselor hasil temuan yang saya lakukan BK masih saja dianggap sebagai tempat untuk siswa yang bermasalah saja, tidak hanya itu guru juga menganggap bahwa tanggung jawab di bidang BK bukanlah hal yang sulit melainkan itu hal yang mudah sehingga banyak guru di bidang mata pelajaran yang menganggap BK tidak terlalu penting pada satuan pendidikan menengah. dalam Permendikbud Nomor 111 Tahun 2014 tentang Bimbingan dan Konseling pada pendidikan dasar dan pendidikan menengah yang menyatakan bahwa setiap sekolah wajib memiliki guru BK yang memiliki standar pendidikan akademik minimal S-1 pada bidang Bimbingan dan Konseling.

atau guru bimbingan dan konseling untuk memfasilitasi perkembangan peserta didik/Konseli untuk mencapai kemandirian dalam kehidupannya. konseli adalah penerima layanan bimbingan dan konseling pada satuan pendidikan.

Miskonsepsi terbentuk karena konsep yang diterima siswa tidak sesuai dengan kebenaranya, siswa dibiarkan memahami dengan sendirinya bahasa dari buku teks tanpa penjelasan yang lebih jelas dari guru mata pelajaran. dalam menyelesaikan miskonsespi pada siswa diperlunya upaya penuntasan masalah klien yang di bantu oleh konselor sesuai dengan aturan yang telah ditetapkan dengan ketentuan layanan bimbingan dan konseling yang bertujuan untuk membantu konseli mencapai perkembangan optimal dan kemandirian secara utuh dalam aspek pribadi, belajar, sosial, dan karir. 


\section{SIMPULAN}

Berdasarkan pembahasan dan hasil temuan ini penulis menyimpulkan beberapa hal terkait temuan penelitian ini yaitu:

- Pelayana BK di SMA sudah sangat membaik dari tahun-tahun sebelumnya. perbaikan layanan Bimbingan dan Konseling dimulai dari program BK sampai ke media yang digunakan. layanan BK yang diberikan di SMA sangat membantu siswa dalam menyelesaikan permasalahannya. dan guru BK di SMA 1 Idi Rayeuk memang guru yang ahli di bidang BK sehingga setiap strategi dan pendekatan yang dilakukan oleh guru BK berdasarkan pada POP BK SMA. untuk layanan BK saat ini di SMA harus di batasi kerena sedang pandemi Covid-19 dan harus mematuhi protokol kesehatan, sehingga guru BK hanya mengangkat permasalahan siswa yang muncul saja seperti tidak hadir kesekolah,tidak megumpulkan tugas,merokok,dan lainnya. sedangkan untuk informasi BK sendiri guru BK akan memberikan arahan dan pemberitahuan melalui media online ( Whatsapp).

- Untuk layanan BK di MAN masih belum berjalan baik karena tidak adanya guru yang ahli di bidang BK itu sendiri, dan untuk layanan yang diberikan mereka lebih ke layanan perorangan atau layanan individu yang mana tujuan nya untuk menyelesaikan permasalahan siswa itu sendiri. untuk program BK itu sendiri di MAN untuk tahun ini tidak ada program apapun, mereka hanya melanjutkan program yang sudah ada sebelumnya. untuk pendekatan yang dilakukan kepada siswa guru BK di MAN hanya berpedoman pada pengalaman pribadi saja dan membaca informasi tentang $\mathrm{BK}$ melalui buku dan lainnya, mereka tidak berpedoman pada POP BK sehingga $\mathrm{BK}$ di MAN tidak berkembang.

\section{DAFTAR PUSTAKA}

Arikunto, S. Prosedur Penelitian Suatu Pendekatan Praktek. Jakarta : PT. Rineka Cipta, 2002, Cet.XII.

Bungin, B. 2008. Analisis Data Penelitian Kualitatif. Raja Grafindo: Jakarta.

Deliani, N. 2018. Konsepsi (Kesalahpahaman) Bimbingan Dan Konseling Dalam Pendidikan. Jurnal Bimbingan dan Konseling, UIN Imam Bonjol Padang, 2018.

Diniaty, A. 2018. Mewaspadai Miskonsepsi Nilai Budaya Dalam Pelaksanaan Konseling Individual: Educational Guidance and Counseling Development ,Jounal, Vol. 1, No. 1, April 2018.

Heldayani, B. 2016. Persepsi Peserta Didik terhadap Pelaksanaan Bimbingan dan Konseling di Sekolah Menengah Atas 
Negeri 1 Karya Penggawa Kabupaten Pesisir Barat, : Jurnal Bimbingan dan Konseling, Volume 3, Nomor 1, 2016.

Moleong, J. L. 2017. Metodologi Penelitian Kualitatif. Bandung : PT Remaja Rosdakary.

Permendikbud. 2014. Tentang Bimbingan Dan Konseling Pada Pendidikan Dasar Dan Pendidikan Menengah, Nomor 111 tahun 2014.

Prayitno. 2013. Dasar-dasar Bimbingan $\mathcal{E}$ Konseling.Jakarta : Rineka Cipta.

Ramlah, 2018. Jurnal Al-Mau'izhah, Pentingnya layanan BK bagi peserta didik, Volume 1 Nomor 1 September 2018.

Rosmalia, L. P. 2016. Miskonsepsi Pembelajaran Matematika Kelas IV Semester II di Sekolah Dasar :Repository Universitas Muhammadiyah Purwokerto.

Sugiyono. 2016. Memahami penelitian kualitatif. Bandung : CV Alfabeta.

Yulianti, Y. 2017. Jurnal Bio Educatio,Miskonsepsi Siswa pada Pembelajaran IPA Serta Remediasinya.Prodi Pendidikan Guru Sekolah Dasar Universitas Majalengka :Volume 2, Nomor 2, Oktober 2017. 